\title{
Percepções do Professor e Pesquisador de Marketing: Um Estudo Qualitativo em Diferentes Países
}

\section{Marketing Professor and Researcher Insights: A Qualitative Study in Different Countries}

\author{
Danilo de Oliveira Sampaio $^{1 *}$, Carlos Henrique Figueiredo e Melo de Brito ${ }^{2}$
}

\begin{abstract}
RESUMO
O objetivo deste estudo foi de verificar, por meio da percepção do professor de Marketing universitário, como é considerado o seu trabalho no ensino e na pesquisa. Para tanto, foi desenvolvida uma metodologia do tipo exploratória de natureza qualitativa. O período de coleta dos dados deu-se entre agosto de 2018 a outubro de 2019 e a análise foi de janeiro de 2020 a abril de 2020, por meio da análise de conteúdo. Foram 14 docentes de marketing entrevistados, sendo estes de 10 diferentes países, África do Sul, Alemanha, Argentina, Brasil, Coreia do Sul, Emirados Árabes, Espanha, Estados Unidos, Itália e Portugal. Após as análises das 6 categorias de estudo, verificou-se que: $\left(1^{\circ}\right)$ a tecnologia é uma importante aliada do docente de Marketing, $\left(2^{\mathrm{a}}\right)$ que os alunos apontam maior necessidade de interação e atualização dos docentes em relação à dualidade "teoria e prática", $\left(3^{\circ}\right)$ que o professor e pesquisador de Marketing sente-se exausto ao ter de cumprir atividades administrativas, de ensino e de pesquisa, visto que a cobrança por aceitação de artigos em periódicos qualificados exigem tempo e investimento na carreira, e que $\left(4^{\circ}\right)$ a cultura do país do docente interfere em diferentes necessidades em relação ao ensino e pesquisa.
\end{abstract}

Palavras-chave: Marketing; Ensino; Pesquisa; Professor; Estudo qualitativo.

\begin{abstract}
The aim of this study was to verify, through the perception of university Marketing professors, how their work in teaching and research is considered. For that, an exploratory qualitative methodology was developed. The data collection period took place between August 2018 and October 2019 and the analysis was from January 2020 to April 2020, through content analysis. There were 14 marketing professors interviewed, these being from 10 different countries, South Africa, Germany, Argentina, Brazil, South Korea, United Arab Emirates, Spain, United States, Italy and Portugal. After analyzing the 6 categories of study, it was found that: (1st) technology is an important ally of the Marketing professor, (2nd) that the students indicate a greater need for interaction and updating of professors in relation to the duality "theory and practice", (3rd) that the Marketing professor and researcher feels exhausted having to carry out administrative, teaching and research activities, since charging for acceptance of articles in qualified journals requires time and investment in a career, and that (4th) the culture of the teacher's country interferes in different needs in relation to teaching and research.
\end{abstract}

Keywords: Marketing; Teaching; Search; Professor; Qualitative study.

\footnotetext{
${ }^{1}$ Universidade Federal de Juiz de Fora (UFJF). Programa de Pós Graduação em Administração (PPGA). Faculdade de Administração e Ciências Contábeis (FACC)

*E-mail: danilo.sampaio@ufjf.edu.br

${ }^{2}$ Universidade do Porto, Portugal (UP). Faculdade de Economia do Porto (FEP).
} 
INTRODUÇÃO: O Saber, A Didática, A Carreira E O Papel Do Professor Nas Ciências Sociais Aplicadas

No que se refere a esta presente pesquisa, procurou-se delimitar o sujeito como sendo o professor universitário da área de Marketing residente e atuante, em diferentes países. Apesar de ser comum artigos que tratam do professor e o seu cotidiano, poucos são os estudos, tanto nacionais quanto internacionais, que verificam o professor universitário de marketing (BACELLAR; IKEDA, 2007). Esta escassez é observada tanto em volume de artigos científicos como em discussões em congressos e seminários.

Quando é relatado o professor de Marketing nos trabalhos científicos já existentes, estes são direcionados, na maioria dos casos, ao perfil do professor. Geralmente, não são considerados outros temas também relevantes, como, quais são as principais teorias e fontes de autores utilizados pelos professores de marketing, ou mesmo, quais são as tendências no ensino e na pesquisa na visão destes professores. Neste contexto, despertouse a seguinte questão-problema: De que forma é visto o ensino e a pesquisa de marketing na visão dos professores deste campo de conhecimento? Diante da questão problema, o objetivo deste trabalho foi de verificar, por meio da visão do professor de marketing universitário, como é considerado o seu trabalho no ensino e na pesquisa.

O professor de Marketing tem uma importante influência para com os alunos de graduação e de pós-graduação, pelo fato de além da teoria, auxiliar os futuros profissionais da área, os quais estarão dirigindo empresas de diferentes setores e tamanhos, tanto nacionais quanto multinacionais. Em termos de justificativa, observa-se uma contribuição importante para a área acadêmica, ao apontar percepções do professor em relação ao ensino e pesquisa de marketing, e assim, verificar aspectos relativos ao seu cotidiano tanto nas aulas de graduação como pós-graduação. Entendendo as percepções dos professores, é viável identificar como ocorre o ensino e a pesquisa do marketing, sugerindo pontos de melhoria e alertas que ocorrem no cotidiano do professor. Até mesmo sugestões às universidades podem ser feitas com base no conhecimento de como se dá o trabalho do professor de marketing, e assim, poder preparar melhor os futuros gestores de organizações. 
A importância de estudar o professor de marketing é melhor observada em países europeus e nos Estados Unidos, visto que nestes países observa-se um maior número de publicações sobre a temática, porém, não em um volume considerável como as demais áreas de estudo no campo da gestão. Mais recentemente, a partir dos anos 2000, podem ser aqui citados alguns periódicos que tratam especificamente do ensino do marketing, como o caso do Internacional Journal for Advancement of Marketing Education e o International Journal of Marketing Education, ambos com artigos e publicações a partir do ano de 2001.

A estrutura deste trabalho além desta introdução, continua com a seção do referencial teórico a respeito do professor de marketing e seu cotidiano, passando para a metodologia, em seguida para a seção de análise dos dados e finalizando com as discussões e considerações finais.

\section{O SABER, A DIDÁtica, A CARREIrA E O PAPEL DO PROFESSOR NAS CIÊNCIAS SOCIAIS APLICADAS}

O professor é visto como um dos propulsores para a educação, conhecimento, dignidade e mesmo um agente importante na empregabilidade do indivíduo. A importância do professor extrapola a sala de aula e atinge fronteiras distantes, para além das expectativas individuais. Em específico nas universidades, o professor tem um papel de formador e orientador de trabalhos, dissertações e teses. É um impulsionador de alunos pesquisadores com inserção social. O professor no ensino superior tem importância no que tange ao desenvolvimento científico, liderando projetos de pesquisa e reunindo alunos no desenvolvimento de iniciativas científicas a favor da sociedade (ALMEIDA; ALONSO, 2007).

Tendo em vista o professor e sua trajetória de carreira, existem desafios e caminhos que podem levar anos de esforços. Em uma Universidade dos Estados Unidos, Buch et al. (2011) realizaram uma pesquisa para verificar as principais barreiras que os professores enfrentam na sua trajetória acadêmica em termos de desenvolvimento da carreira. Os autores se concentraram em estudar nos Estados Unidos como o professor associado podem chegar ao cargo de professor titular. Dentre outros aspectos, Buch et al. (2011) concluem que é fundamental apresentar critérios claros de como o professor pode ascender na carreira; que as atividades de ensino, pesquisa e de gestão devem ser 
distribuídas entre os professores sem concentrar alguns em detrimento de todos; que deve haver respeito e distribuição de atividades de forma igual em relação ao gênero; que é importante haver acompanhamento da carreira do professor por parte da Universidade e, por fim; é necessário apresentar feedbacks para que o professor possa construir sua carreira melhor.

O stress é outro tema pesquisado quando se fala no professor. Jepson e Forrest (2006) ao estudarem os fatores que contribuem para o stress ao entrevistarem 95 professores no Reino Unido, citam que a personalidade de cada indivíduo influencia no nível do stress, bem como os fatores considerados ambientais, como o volume de trabalho e a necessidade de aprendizagem constante. As autoras corroboram com os achados de Travers e Cooper (1996) e Cox (1978), os quais apontam que a maneira como o professor encara seus desafios em termos de expectativas em relação ao alcance dos seus objetivos, pode levar a um nível maior de stress de acordo com cada personalidade em específico. Jepson e Forrest (2006) identificaram que existe forte correlação entre os esforços que o professor passa em detrimento da sua realização profissional e o stress percebido. As autoras citam que os professores com maior desempenho e com compromisso ocupacional elevado, possuem mais stress no trabalho.

Segundo Costa et al. (2011) existem dois fatores atribuídos a este cenário sobre o qual o professor de Administração se encontra no Brasil. O primeiro fator é o modelo empregado do ensino de Administração desde o final da década de 1960, quando devido ao crescimento industrial brasileiro, era necessário ter gestores em quantidade e com perfil voltado a resultados. Vergara (2007) corrobora e ainda cita que a qualidade do ensino de Administração nesta época foi de baixa qualidade, visto que o foco estava na quantidade e não qualidade. O segundo fator é a metodologia mecanizada de aula, na qual não é dada autonomia ao aluno e é concentrado ao professor o repasse do conhecimento de forma repetitiva. Neste escopo é o que Freire (1987) denomina de educação bancária, ou seja, a centralização do ensino no professor que se julga o "dono do saber", conforme aponta o autor.

Para atenuar e mesmo auxiliar a didática do professor de Administração, De La Torre (2008) aponta a necessidade de investir nas aulas um ambiente de maior interação e resolução de problemas e simulações, assim a dinâmica pode ser uma aliada no processo de ensino-aprendizagem. Corroboram Knowles, Holton e Swason (2009), que destacam a importância de a capacidade crítica dos alunos ser despertada nas atividades em equipes. 
Desta forma, a concentração do professor é diluída, envolvendo os alunos nas atividades em sala de aula.

\section{O PROFESSOR DE MARKETING}

Tratando do escopo do professor de Marketing, mesmo sendo pouco pesquisado tanto no Brasil quanto em outros países, observa-se mais trabalhos vindos do exterior. Este fato é corroborado por Bacellar e Ikeda (2006). As autoras desenvolveram uma pesquisa qualitativa para verificar as perspectivas e caminhos do professor de Marketing. Segundo as autoras, os primeiros periódicos internacionais sobre temas referentes ao professor de marketing são o The Journal of Marketing em 1936, o Journal of Marketing Education em 1979, o Marketing Education Review em 1991, o Journal of Marketing for Higher Education em 1992, o International Journal for Advancement of Marketing Education já em 2001 e o International Journal of Marketing Education também em 2001.

Nas fontes bibliográficas selecionadas neste trabalho, verificou-se que de fato, ocorrem diferentes discussões e investigações em relação ao trabalho do professor de Marketing, com destaque para cinco pontos: (1) a relação entre o professor e os alunos; (2) a metodologia e didática de aulas e da pesquisa utilizada pelos professores; (3) trabalhos de extensão e administrativos do professor; (4) a pressão por resultados ligada a produtividade científica e ao volume de aulas; e (5) ao distanciamento do professor de marketing com as empresas em termos de troca de conhecimentos e parcerias.

Peters (1980) ao entrevistar professores em sua pesquisa dos Estados Unidos e Inglaterra, já destacava que ocorria nos Estados Unidos um distanciamento entre os professores e os executivos de marketing para com o conceito e utilização do marketing nas empresas, o que não ocorria na Inglaterra, segundo o autor. Nas análises das entrevistas realizadas por Peters (1980), verificou-se que na Inglaterra, muitos executivos e mesmo empresários, não tinham tempo para se dedicar em universidades de excelência pois tinham logo que trabalhar nas empresas, e que uma forma de melhorar o conhecimento de marketing deles foi criar cursos de mestrado formatados e mais adequados à realidade destes executivos, e assim, permitiu capacitar e formar conhecimentos mais sólidos e acadêmicos de marketing sem maiores rigores do que uma disciplina ou formação restrita para a teoria. 
Ikeda e Bacellar (2008) desenvolveram um estudo em universidades brasileiras com o objetivo de levantar a perspectiva de professores de Marketing em relação aos alunos de diferentes níveis: graduação e pós-graduação. As autoras utilizaram como base a grounded theory e realizaram entrevistas em profundidade com alunos de graduação e pós-graduação. As autoras chegaram à conclusão de que os professores de Marketing preferem dar aula para o mestrado e doutorado seguido da graduação e depois da especialização.

Gruber et al. (2012) realizaram uma pesquisa nos Estados Unidos com alunos de graduação de Marketing, para verificar o que mais deixa os alunos satisfeitos como também insatisfeitos em relação aos atributos e perfil do professor. Os fatores que mais satisfazem aos alunos são conhecimento do professor, variedade de método de ensino, e promover atividades em equipes. Já os fatores que tornam os alunos menos satisfeitos passam pela a falta do professor em envolver os alunos, melhoria da aprendizagem por meio da ajuda aos alunos nas atividades e manter relações mais harmoniosas com os alunos incluindo a empatia, o entusiasmo e o humor.

\section{METODOLOGIA}

A metodologia utilizada foi do tipo exploratória de natureza qualitativa, visto que o foco foi estudar o ensino e pesquisa de acordo com a percepção do sujeito da pesquisa, sendo este o professor de marketing nos cursos de gestão em universidades. A pesquisa exploratória verifica como ocorrem relações entre o objetivo da pesquisa e as percepções do indivíduo sujeito do estudo. Optou-se na realização de entrevistas a 14 docentes de Marketing, por meio de um roteiro semiestruturado. As entrevistas, conforme aponta Manzini (1990), possibilitam interação social, sendo possível identificar subjetividades e percepções dos entrevistados.

Na pesquisa exploratória uma importante finalidade é basear a fundamentação dos dados coletados nas experiências reais dos sujeitos, o que leva em consideração o seu vocabulário, ambiente de vida e também suas percepções e subjetivismos (Creswell, 2010). Malhotra (2001) destaca que na pesquisa exploratória geralmente a amostra é pequena, sugerindo uma análise de dados qualitativa.

Segundo Gaskell (2002) a pesquisa qualitativa buscar desenvolver e compreender as relações entre os atores sociais e a sua situação, que neste caso, trata compreender as 
relações dos professores de marketing com seu trabalho de ensino e pesquisa. A natureza qualitativa não indica conclusões a respeito de um fenômeno, mas sim riqueza de dados e informações sobre um determinado assunto ou sujeito de pesquisa, que traz um rico acervo de possibilidade de análises. Segundo Denzin e Lincoln (1994) a pesquisa qualitativa possibilita encontrar respostas para as questões baseadas na experiência social. Para o tratamento dos dados, optou-se pela análise de conteúdo, sendo esta técnica adequada ao objetivo proposto no trabalho.

A análise de conteúdo é um conjunto de técnicas de análise das comunicações que por procedimentos sistemáticos e objetivos de descrição do conteúdo das mensagens, objetivam ter indicadores (quantitativos e/ou qualitativos) que permitam a inferência de conhecimentos relativos às condições de produção/recepção (variáveis inferidas) destas mensagens (BARDIN, 2011, p. 47).

Nesta pesquisa seguiu-se as três fases segundo Bardin (2011): ( $1^{\mathrm{a}}$ fase) pré-análise (objetivo, teoria, organização do roteiro de entrevista sobre o trabalho); ( $2^{\mathrm{a}}$ fase) exploração do material (transcrição das entrevistas gravadas, uso dos artigos selecionados e anotações; criação das categorias de análise); e ( $3^{\mathrm{a}}$ fase) tratamento dos dados (interpretação dos conceitos do marco teórico em forma de análise e resultados).

As entrevistas foram gravadas e transcritas para a análise dos dados, lembrando que a cada entrevistado, foi explicado o objetivo da pesquisa, sendo necessária a concordância voluntária para a participação, ao assinar um termo livre e esclarecido sobre o estudo. Foi utilizado o software webQDA® (Qualitative Data Analysis) e o Skype ${ }^{\circledR}$ como apoio. O webQDA® segundo Souza et al. (2011), permite analisar os dados por três aspectos: ( $1^{\circ}$ aspecto) fonte (nesta pesquisa foi o caso das transcrições das entrevistas), ( $2^{\circ}$ aspecto) codificação (momento da criação das categorias de análise), e ( $3^{\circ}$ aspecto) questionamento (momento de questionar os dados categorizados e buscar as respostas ao problema de pesquisa), ou seja, a centralização do ensino no professor que se julga o "dono do saber", conforme aponta o autor.

Para atenuar e mesmo auxiliar a didática do professor de Administração, De La Torre (2008) aponta a necessidade de investir nas aulas um ambiente de maior interação

\author{
ANÁLISE DOS DADOS \\ PERÍODO DE COLETA, TIPO E PERFIL DA AMOSTRA
}


A coleta dos dados ocorreu entre agosto de 2018 a outubro de 2019, já a análise dos dados foi de janeiro a abril de 2020. Foram 14 professores de marketing entrevistados, sendo 8 entrevistas presenciais e 6 virtuais. Os professores lecionam na graduação e pósgraduação em 10 diferentes países, sendo: África do Sul, Alemanha, Argentina, Brasil, Coreia do Sul, Emirados Árabes, Espanha, Estados Unidos, Itália e Portugal (tabela 1).

Tabela 1 - Perfil da amostra: professores de marketing entrevistados

\begin{tabular}{|c|c|c|c|c|c|}
\hline Id & $\begin{array}{c}\text { Graduação dos } \\
\text { professores }\end{array}$ & $\begin{array}{c}\text { Doutorado dos } \\
\text { professores }\end{array}$ & $\begin{array}{l}\text { País onde } \\
\text { leciona }\end{array}$ & $\begin{array}{l}\text { Disciplina que leciona } \\
\text { de maior carga horária }\end{array}$ & $\begin{array}{c}\text { Tipo de } \\
\text { entrevista }\end{array}$ \\
\hline P1 & Administração & Administração & África do Sul & Marketing & Online \\
\hline $\mathrm{P} 2$ & Administração & Marketing & Alemanha & $\begin{array}{l}\text { Estratégia de } \\
\text { Marketing }\end{array}$ & Presencial \\
\hline P3 & Administração & Administração & Argentina & Marketing & Online \\
\hline $\mathrm{P} 4$ & Administração & Administração & Brasil & Marketing & Online \\
\hline P5 & Administração & Administração & Brasil & $\begin{array}{l}\text { Comportamento do } \\
\text { Consumidor }\end{array}$ & Presencial \\
\hline P6 & Administração & Marketing & $\begin{array}{l}\text { Coreia do } \\
\text { Sul }\end{array}$ & Marketing & Online \\
\hline P7 & Administração & Administração & $\begin{array}{l}\text { Emirados } \\
\text { Árabes }\end{array}$ & Marketing & Online \\
\hline P8 & Comunicação & Marketing & Espanha & Marketing de Serviços & Presencial \\
\hline P9 & Administração & Marketing & $\begin{array}{l}\text { Estados } \\
\text { Unidos }\end{array}$ & Branding & Presencial \\
\hline $\mathrm{P} 10$ & Economia & Economia & Itália & Marketing e Inovação & Presencial \\
\hline P11 & Administração & Administração & Portugal & $\begin{array}{l}\text { Comportamento do } \\
\text { Consumidor }\end{array}$ & Presencial \\
\hline P12 & Marketing & Marketing & Portugal & Marketing B2B & Presencial \\
\hline P13 & Marketing & Marketing & Portugal & $\begin{array}{l}\text { Introdução ao } \\
\text { Marketing }\end{array}$ & Presencial \\
\hline P14 & $\begin{array}{c}\text { Relações } \\
\text { Internacionais }\end{array}$ & Marketing & Portugal & $\begin{array}{c}\text { Comunicação } \\
\text { Integrada de } \\
\text { Marketing }\end{array}$ & Online \\
\hline
\end{tabular}

Fonte: os autores (2020)

Para preservação das identidades dos respondentes e das universidades, cada professor foi identificado por um código (Id), entre P1 a P14. Em relação à duração das 
entrevistas, o tempo médio foi de 129 minutos. A amostra foi do tipo não probabilística, intencional e por conveniência, respeitando as condições de viabilidade do pesquisador, aliando o modelo presencial e online de entrevistas. Sobre os professores, além de ministrar aulas, alguns líderes de grupos de pesquisa, atividade encontrada em todos eles.

\section{CATEGORIAS DE ANÁLISE E ROTEIRO DE ENTREVISTA}

As categorias ou códigos de análise refletem o conteúdo visto na teoria. As categorias para Bardin (2011) surgem das questões norteadoras. A organização destas categorias possibilita o trabalho dos temas e mesmo dos indicadores. Foram criadas 6 categorias as quais, por sua vez, são formadas pelas respectivas subcategorias (quadro 1).

QUADRO 1: Categorias e subcategorias de análise. Fonte: os autores (2020)

\begin{tabular}{|c|c|c|c|}
\hline & ategorias (Cat) & & Subcategorias (Sub) \\
\hline \multirow[t]{2}{*}{ Cat 1} & \multirow{2}{*}{$\begin{array}{l}\text { Ser professor e } \\
\text { pesquisador de } \\
\text { marketing }\end{array}$} & Sub 1.1 & $\begin{array}{l}\text { Principais áreas e linhas de ensino e pesquisa de marketing } \\
\text { do professor }\end{array}$ \\
\hline & & Sub 1.2 & Opinião e percepção sobre o professor de marketing \\
\hline \multirow{5}{*}{ Cat 2} & \multirow{5}{*}{$\begin{array}{l}\text { Ensino de } \\
\text { marketing }\end{array}$} & Sub 2.1 & $\begin{array}{l}\text { As dificuldades que o professor de marketing enfrenta no } \\
\text { ensino }\end{array}$ \\
\hline & & Sub 2.2 & $\begin{array}{l}\text { As oportunidades que o professor de marketing enfrenta no } \\
\text { ensino }\end{array}$ \\
\hline & & Sub 2.3 & $\begin{array}{l}\text { Quais os métodos de ensino que o professor mais utiliza no } \\
\text { marketing }\end{array}$ \\
\hline & & Sub 2.4 & Interesse ou não dos alunos pelo ensino de marketing \\
\hline & & Sub 2.5 & Tendências do ensino em marketing \\
\hline \multirow{5}{*}{ Cat 3} & \multirow{5}{*}{$\begin{array}{l}\text { Pesquisa de } \\
\text { marketing }\end{array}$} & Sub 3.1 & $\begin{array}{l}\text { As dificuldades que o professor de marketing enfrenta na } \\
\text { pesquisa }\end{array}$ \\
\hline & & Sub 3.2 & $\begin{array}{l}\text { As oportunidades que o professor de marketing enfrenta na } \\
\text { pesquisa }\end{array}$ \\
\hline & & Sub 3.3 & $\begin{array}{l}\text { Os métodos de pesquisa que o professor mais utiliza no } \\
\text { marketing }\end{array}$ \\
\hline & & Sub 3.4 & Interesse ou não dos alunos pela pesquisa de marketing \\
\hline & & Sub 3.5 & Tendências da pesquisa em marketing \\
\hline Cat 4 & $\begin{array}{l}\text { Desenvolvimento } \\
\text { sustentável e } \\
\text { marketing }\end{array}$ & Sub 4.1 & $\begin{array}{l}\text { Verifica se o professor realiza ou se já realizou pesquisas de } \\
\text { marketing incluindo temas de desenvolvimento sustentável }\end{array}$ \\
\hline Cat 5 & $\begin{array}{l}\text { A voz do } \\
\text { professor de } \\
\text { marketing }\end{array}$ & Sub 5.1 & $\begin{array}{l}\text { Percepção e opinião livre sobre a profissão de professor e } \\
\text { pesquisador de marketing }\end{array}$ \\
\hline Cat 6 & $\begin{array}{l}\text { Envolvimento } \\
\text { empresa } X \\
\text { universidade X } \\
\text { marketing }\end{array}$ & Sub 6.1 & $\begin{array}{l}\text { Verifica se o professor julga importante a relação direto do } \\
\text { envolvimento de empresas junto às universidades no caso } \\
\text { dos estudos de marketing }\end{array}$ \\
\hline
\end{tabular}

Fonte: Fonte: os autores (2020) 
Para compreender melhor a relação das categorias e subcategorias utilizadas na investigação pode-se verificar por meio de um gráfico de árvore (figura 1).

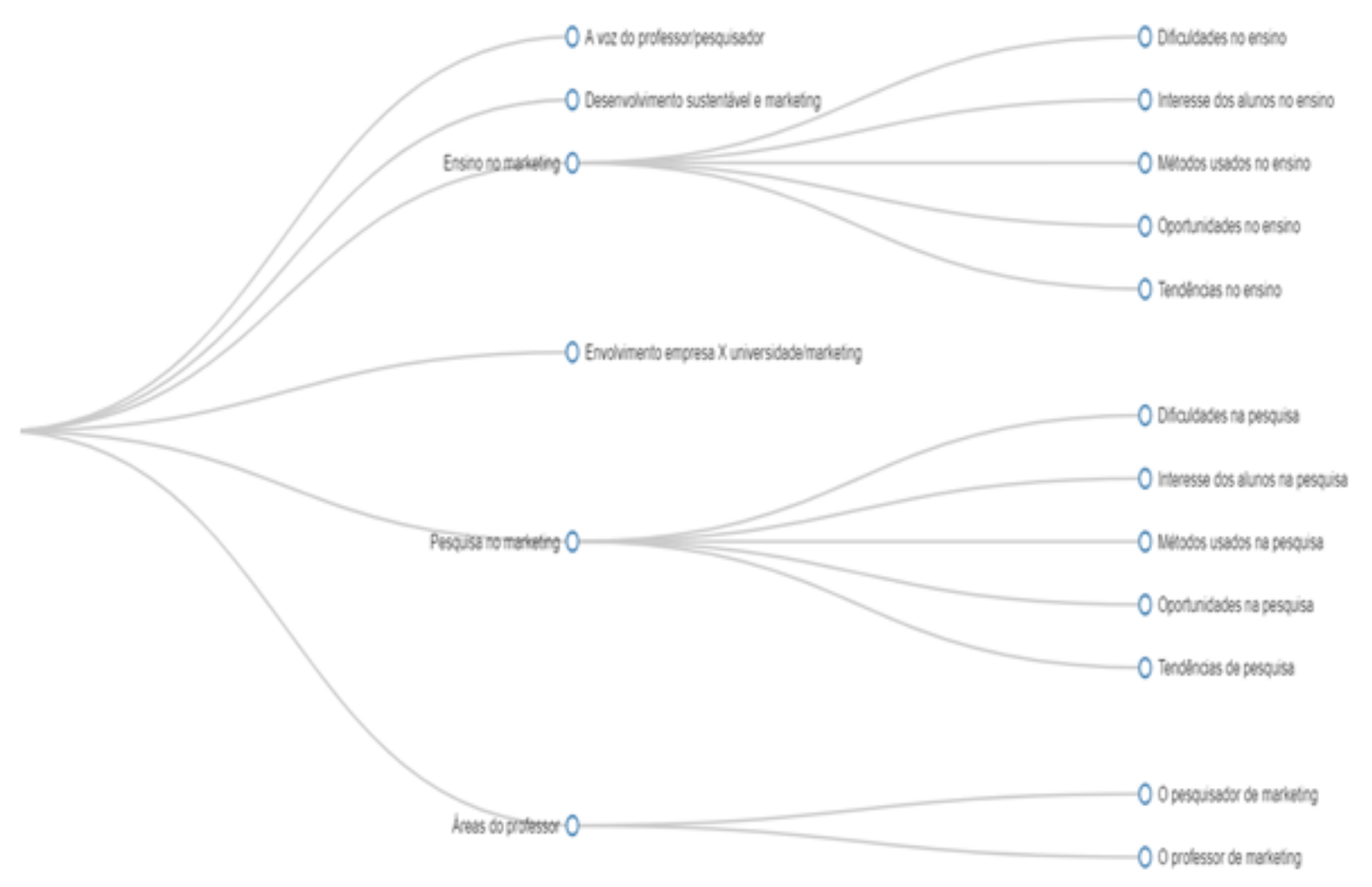

FIGURA 1: Relação entre categorias e subcategorias de análise em forma de árvore Fonte: os autores (2020) por meio do software webQDA ${ }^{\circledR}$

Em relação a frequência dos termos mais citados pelos professores de marketing, a figura 2 ilustra segundo a nuvem de palavras mais frequentes.

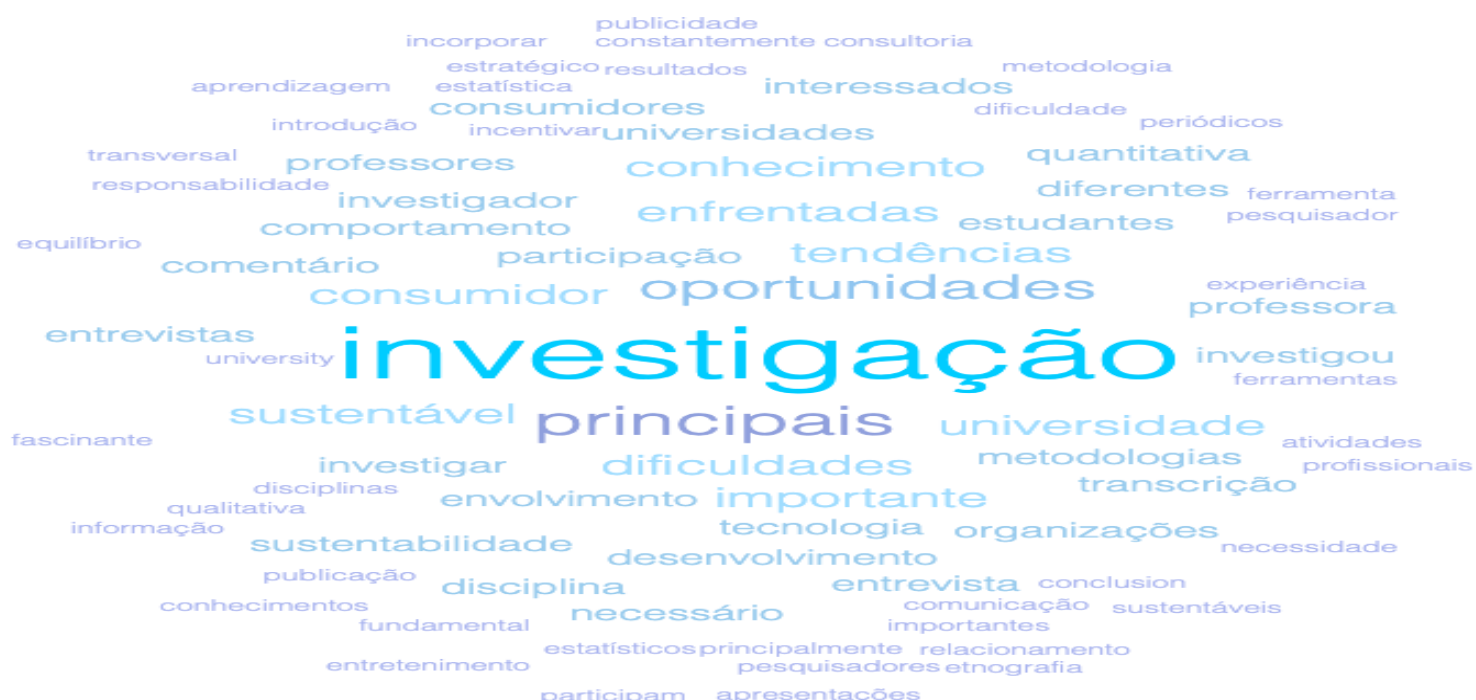

FIGURA 2: Relação entre categorias e subcategorias de análise em forma de árvore Fonte: os autores (2020) por meio do software webQDA ${ }^{\circledR}$ 
As cinco (05) palavras mais citadas nas falas dos professores entrevistados foram: investigação (114 repetições); principais (57 repetições), oportunidades (34 repetições), dificuldades (32 repetições) e tendências (30 repetições). $O$ fato de os professores serem pesquisadores, fez com que a palavra "investigação" fosse frequente, mas o destaque maior ocorre nos termos "oportunidades" e "dificuldades", as quais foram muito citadas por estarem no cotidiano dos entrevistados. Já a palavra "principais", foi vista sempre próxima as outras já apontadas, "oportunidades" e "dificuldades", que faz tornar evidente o olhar do professor de marketing para aspectos que são dificultadores e facilitadores do seu trabalho. As categorias de análise podem ser vistas também na relação com todos os 14 professores interessados (figura 3), onde estão relacionadas as categorias e subcategorias incluindo os professores, demonstrando que o roteiro semiestruturado foi integralmente respondido.

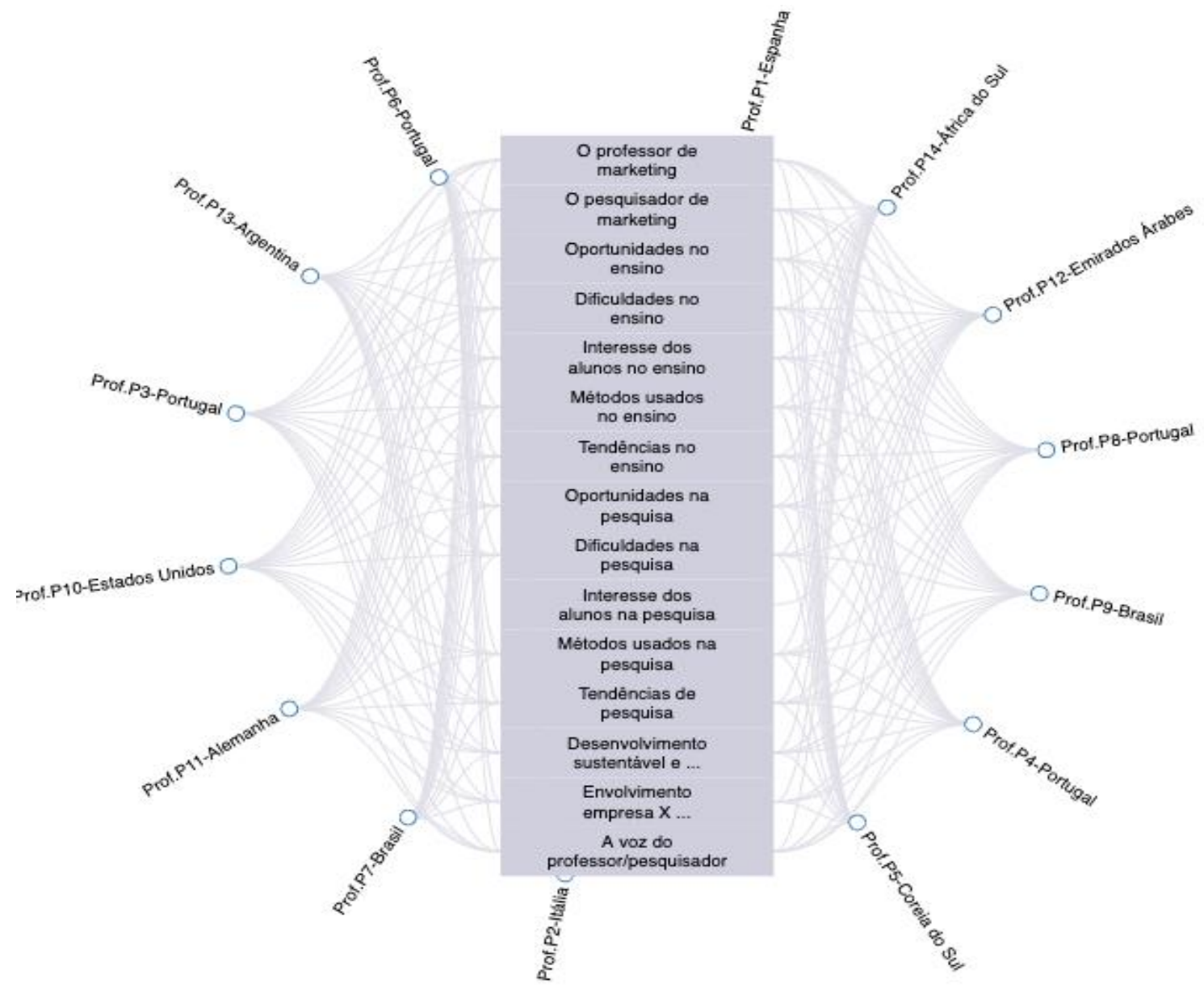

FIGURA 3: Relação entre categorias e subcategorias de análise em forma de árvore Fonte: os autores (2020) por meio do software webQDA ${ }^{\circledR}$ 
Sobre o roteiro semiestruturado (figura 4), este foi aplicado a cada professor individualmente. Com 12 questões do tipo aberta o roteiro está dividido em 6 partes: $\left(1^{\mathrm{a}}\right.$ parte) duas questões para "quebrar o gelo" sobre a área e a percepção de ser professor; ( $2^{\mathrm{a}}$ parte) quatro questões sobre o ensino de marketing; ( $3^{\mathrm{a}}$ parte) quatro questões sobre a pesquisa de marketing e uma sobre desenvolvimento sustentável e relação com o marketing; ( $4^{\mathrm{a}}$ parte) uma questão aberta sobre a opinião do professor; ( $5^{\mathrm{a}}$ parte) termo de autorização e uso dos dados; e ( $6^{\mathrm{a}}$ parte) identificação e dados do professor, universidade e cargo.

\section{Necessária a gravação de voz - Required voice recording}

PERGUNTAS PARA OUEBRAR O GELO (OUESTIONS TO BREAK THE ICE)

1. Qual é a sua principal área de ensino e investigação em Marketing?

(What is your main area of teaching and research in Marketing?)

2. Para si o que é ser Professor e/ou Investigador na área de Marketing?

(For you what is a marketing Professor and Researcher)?

PERGUNTAS SOBRE ENSINO (OUESTIONS ABOUT TEACHING)

3. Quais são as principais oportunidades ou dificuldades enfrentadas no ensino do Marketing?

(What are the main opportunities or difficulties faced in marketing teaching)

4. Qual a sua opinião sobre a participação e interesse dos alunos de Marketing?

(What is your opinion about the participation and interest of Marketing students?)

5. Quais são os principais métodos de ensino que utiliza nas suas aulas de Marketing?

(What are the main teaching methods you use in your marketing classes?)

6. Na sua opinião quais são as grandes tendências no dominio do ensino do Marketing?

(In your opinion what are the major trends in the field of Marketing education?)

PERGUNTAS SOBRE INVESTIGACÃO (QUESTIONS ON RESEARCH)

7. Quais são as principais oportunidades ou dificuldades enfrentadas na investigação em Marketing?

(What are the main opportunities or difficulties faced in Marketing research?)

8. Qual a sua opinião sobre o envolvimento das empresas e outras organizações na investigação que faz em Marketing?

What is your opinion about the involvement of companies and other organizations in the research you do in Marketing?)

9. Quais são as principais metodologias de pesquisa que utiliza na investigação que faz em Marketing?

(What are the main research methodologies that you use in your marketing research?)

$10 . \mathrm{Na}$ sua opinião quais são as grandes tendências no dominio da investigação em Marketing?

(In your opinion what are the major trends in the field of Marketing research?)

11. Já investigou ou pretende investigar sobre a relação do Marketing com o Desenvolvimento Sustentável?

(Have you ever investigated or intend to investigate the relationship between Marketing and Sustainable

Development)

CONCLUSAOO (CONCLUSION)

12. Para terminar gostaria de deixar algum comentánio sobre o Ensino e Investigação em Marketing?

(To conclude would you like to give a comment about Marketing Research and Teaching?)

Autorização do uso de nome (Authorization to use name)

Autoriza a divulgação do seu nome para fins acadêmicos?

(Authorize the disclosure of your name for academic purposes?)

- [ ] Sim autorizo a divulgação de meu nome para fins acadêmicos e cientificos.

(Yes, I authorize the disclosure of my name for academic and scientific purposes.)

- [ ] Nào autorizo a divulgação de meu nome para fins acadêmicos e cientifícos. (I do not authorize the disclosure of my name for academic and scientific purposes.)

Dados do entrevistado (Data of the professor interviewed)

- Nome completo: (F ull name)

- E-mail (para envio de link da survey) (e-mail to send survey link):

- Universidade/Faculdade: (University/Faculty:)

- Pais: (Country)

Cidade: (City)

- Cargo do Professor - Pesquisador de Marketing - (Position of Professor/ Marketing Researcher ):

- Disciplina de Marketing que ministra atualmente - (Marketing discipline that you are currently teaching):

FIGURA 4: Roteiro semiestruturado aplicado aos professores de entrevistados Fonte: os autores (2020) 


\section{ANÁLISE DO CONTEÚDO}

Após a realização das 14 entrevistas foram analisadas as transcrições das mesmas. Dentre os aspectos relevantes, destaca-se a fala de cada professor por categoria. Sobre a categoria 1 (ser professor e pesquisador de marketing), sete professores citaram que ministram a disciplina de Marketing, seguida de comportamento do consumidor, branding e marketing de serviços. Os professores destacam que na área de Marketing, é necessário atualizar leituras e estudo, publicação e dedicação, além de ser uma profissão que fornece valor para a vida.

Para atenuar e mesmo auxiliar a didática do professor de Administração, De La A metodologia utilizada foi do tipo exploratória de natureza qualitativa, visto que o foco foi estudar o ensino e pesquisa de acordo com a percepção do sujeito da pesquisa,

Para mim o professor de marketing tem de ser investigador e ao mesmo tempo um bom professor em sala de aula. Ele tem de ter prática de ensino e fazer pesquisas. O professor de marketing tem de ler muito, entender, dominar e exemplificar aos alunos as ferramentas de marketing. Exige contato com o mercado e com as empresas (P6).

Não é uma questão fácil de responder. O professor de marketing tem de publicar em excelentes journals e periódicos. No meu caso o primeiro objetivo é ajudar as empresas e entender como a pesquisa pode ajudar na decisão dessas empresas e unir a academia e talentos de estudantes a ajudar estas empresas. Promover jovens talentos para formar os empregos nas empresas (P2).

Sobre a categoria 2 (ensino de marketing), ocorreram depoimentos com poucas divergências, em se tratando das dificuldades e oportunidades enfrentadas. O entrevistado P1 cita que no continente europeu, o professor em regime parcial sem exclusividade, divide seu tempo de trabalho em diferentes universidades. Este fato interfere na dedicação às pesquisas.

Na Europa, para ministrar aulas, o professor escolhe o tipo de carreira ou carga horária de acordo com a classificação, sendo professor parcial ou professor integral. $\mathrm{O}$ professor integral geralmente tem mais tempo para se dedicar na pesquisa e possui maior titulação e experiência. Assim as universidades conseguem ter cursos acreditados. A acreditação na Europa é uma forma de valorizar cursos com qualidade superior. Tem diferentes níveis de professor. No meu caso eu dou aulas em duas universidades e sou professor parcial nas duas universidades (P1). 
O entrevistado P9 observa que uma dificuldade encontrada está na falta de investimento em recursos materiais e humanos em relação a estrutura e funcionamento das universidades. Isto pode impactar no desempenho dos alunos.

Sem dúvida os recursos materiais e humanos são imprescindíveis. Uma sala de aula adequada e estrutura de tecnologia são fundamentais. Os alunos que estudam e trabalham enfrentam dificuldades e o professor tem de entender e praticar técnicas de envolvimento. Nem todos os alunos são motivados e isso é um fato (P9).

Sobre o interesse dos alunos no ensino de marketing, verificou-se que o professor deve ser criativo e utilizar casos envolventes de marketing nas aulas. Os professores entrevistados entendem que o aluno não tem mostrando interesse e envolvimento nas aulas de marketing, mas que, quando o professor consegue relatar casos reais de marketing nas empresas ou quando a experiência do professor por meio da metodologia consegue a tenção dos alunos, existe mais comprometimento dos alunos. Promover trabalhos em equipes entre os alunos desperta a motivação dos mesmos pelo ensino de marketing, repassando autonomia e responsabilidades.

Têm alunos mais interessados e menos interessados. Aqueles que se dedicam mais e outros menos. O professor tem de chamar atenção e saber repassar o conhecimento adequadamente (P13).

Em geral os estudantes têm muito interesse em gestão, finanças e o marketing são os mais procurados pelos estudantes. Marketing e comunicação despertam muito interesse. Muitas oportunidades de trabalho na área de vendas e na área digital despertam o interesse pelos alunos na área de marketing (P4).

Eu tento envolver os alunos mostrando a relação entre a disciplina de marketing e as empresas e organizações. O marketing em geral é uma área de consumo diferente de finanças ou contabilidade. Os alunos já vêm com uma ideia de marketing porque são consumidores. Os alunos não sabem o que é marketing, mas já possuem uma ideia a respeito. Os alunos têm que entender que o marketing envolve comas outras áreas do negócio, com investimentos, com o valor da marca (P1).

Os alunos devem ser despertados para o ensino. Os alunos tem de ser envolvidos pela didática e conteúdo do professor. Trabalhos em equipes são importantes (P14).

Em específico a métodos de ensino e tendências do ensino de marketing, os professores mesmo em diferentes países destacam os estudos de caso, interação em equipes, aulas expositivas e participativas com apresentações de trabalhos e o uso de 
tecnologias móveis e interativas. Os professores entrevistados apontam para uma aula de marketing mais dinâmica, com atividades externas e utilizem softwares e aplicativos, para demonstrar a relação entre teoria e prática. Também ocorre preferência por metodologias de natureza quantitativa nas atividades desenvolvidas pelos professores.

\begin{abstract}
Surveys e estudos quantitativos no campo do marketing de relacionamento e comportamento do consumidor. Tecnologia e ferramentas como big data (P12).

$\mathrm{Na}$ graduação e mestrado os estudos de casos e como o marketing funciona na prática. Métodos mistos e pesquisa de marketing são fundamentais. A tecnologia é na minha opinião muito importante. Uso o intercâmbio dos alunos com outras culturas e universidades (P10).

$\mathrm{Na}$ graduação e pós-graduação tento trazer representantes de empresas nas aulas e também utilizo estudo de caso. Não somos uma ciência da vida, e não temos laboratórios, então uso o estudo de caso. Uso também o confronto de alunos contra outros, para resolver casos. Já outro grupo apresenta o caso de ensino. Implica maior envolvimento pois os alunos devem estar dentro na sala para apresentar e desafiar (P3).

Ensinar Marketing na Coreia do Sul é diferente do que na Europa. Aqui deve se ter mais aproximação com os alunos, envolver mais os alunos no ensino (P5).
\end{abstract}

Na categoria 3 (pesquisa de marketing), da mesma forma como visto no ensino, não ocorrem muitas diferenças na visão dos professores sobre tendências e envolvimento dos alunos. Entretanto, observa-se que na pesquisa um aprofundamento de estudos, principalmente em termos metodológicos e teóricos.

Faço uso de pesquisa quantitativa e qualitativa, mas a pesquisa quantitativa, testando hipóteses e experimentos são as que mais utilizo. Verifico o comportamento dos consumidores em relação à marca (P14). Eu dou aula no mestrado de Administração. Cerca de $75 \%$ dos alunos trabalham em alguma empresa em cargos executivos. Eles demandam tanto aulas com foco em pesquisa como também no desenvolvimento dos negócios. Eu também tenho contato com oito universidades e isto tem que gerar administração de tempo. Marketing em negócios é diferente de marketing acadêmico. Muitos alunos ainda chegam confundindo marketing com publicidade. Isto é perverso (P1).

Nas aulas de mestrado e doutorado, minha preferência é pela pesquisa experimental com uso de estatística multivariada. A teoria de marketing deve ser profundamente entendida pelo pesquisador para que possam ser propostos novos conhecimentos e estudos inéditos na área (P5).

Uso mais pesquisa qualitativa com entrevistas e alguns estudos estatísticos. Uso mais psicologia e antropologia do que estatística (P2). No doutorado prefiro utilizar pesquisa experimental com uso de estatística multivariada. Em alguns casos a pesquisa qualitativa ocorre, mas com menor frequência. Provoco o uso de tecnologia e a busca de dados dos consumidores de diferentes países no marketing (P11). 
Os professores destacam que para a pesquisa é necessário muito tempo de preparação de aulas, exigindo ainda mais do professor. Também são colocados alguns aspectos sobre a tendência da pesquisa de marketing, como o uso mais intenso de tecnologias de informação, ensino digital a distância, experiência de consumo e cultura, estudos sobre marketing e desenvolvimento sustentável, e temas que envolvam a sociedade e o marketing.

O que tenho visto é incentivo a aulas a distância, plataformas de ensino a distância. Uso do Skype para orientação de pesquisa e trabalhos de conclusão de curso. Uso de tecnologias (P7). Marketing é diferente de uma disciplina como Estatística. Podemos usar vídeos e casos. A tecnologia é outra área que o marketing estuda. A tendência é algo importante, mas o marketing deve ser visto no campo das empresas, no dia a dia (P1). Vejo o ensino de marketing vinculado ao digital, games, aplicativos, quiz, perguntas e respostas. E o ensino ligando o marketing ao valor da sociedade e sustentabilidade, inclusão social e direitos de mulheres (P8). A tecnologia e a interação de experiências, com a troca de conhecimento com culturas diferentes (P10).

Na categoria 4 (desenvolvimento sustentável e marketing), quando perguntado aos professores de marketing se já investigaram marketing e relações com o desenvolvimento sustentável, verificou-se que em alguns casos ocorre este tipo de estudo, já em outras falas, há intenção, mas ainda não houve oportunidade. De uma forma geral, os professores entendem ser o desenvolvimento sustentável é uma área de interesse em marketing.

No setor de moda e luxo, já orientei vários estudos de sustentabilidade. Marcas e associação a sustentabilidade. Responsabilidade social e relatórios de sustentabilidade. É importante para o Marketing estudar o ciclo de vida do produto e ligar isto atitudes sustentáveis. Outro trabalho que orientei foi sobre usina de biocombustível e reciclagem (P7).

Sim, pois é a minha área de investigação. Promover práticas mais sustentáveis em sala de aula contando com artigos e exemplos de práticas sustentáveis. Incentivo a relação de bem estar e marketing social (P8).

Ainda não relacionei marketing e desenvolvimento sustentável, mas reconheço que é uma área muito importante e traz muitas oportunidades de pesquisa (P5).

Esta é exatamente uma área que entendo como muito importante. O marketing verde e o consumo sustentável são temas de interesse do meu grupo de pesquisa (P3).

Na categoria 5 (a voz do professor de marketing), foi direcionada aos professores uma opção livre para deixar qualquer tipo de comentário ou opinião, desde que a respeito 
sobre ser professor e/ou pesquisador de marketing. Todos os entrevistados se sentiram confortáveis em colocar suas considerações, principalmente citando o prazer de trabalhar com marketing. Foi também observado um espaço de angústia e sentimento de maior valorização tanto pela profissão de professor quanto de incentivo a pesquisas. Seguem algumas falas neste sentido.

O marketing é fascinante e necessário para a academia e para as empresas. Aliar pesquisadores e empresas e reservar capital para pesquisas em marketing, bolsas de estudo e estrutura de trabalho são muito importantes para a melhoria da área. Fornecer ao professor mais recursos e apoio também é necessário, pois a pressão por resultados na academia é rigorosa (P14).

Mais necessidade de prática pelos professores que ensinam marketing. Devem existir mais praticantes de marketing e não só teóricos. Os estudantes precisam aprender como o marketing é usado nas empresas. Os professores são responsáveis pela transmissão de conhecimento do marketing (P1).

Selecionar periódicos e journals fortes é muito difícil para o meu caso de professor em meio período. Publicar hoje é muito difícil até para professor full time. É importante muitos estudos principalmente estatísticos e dados, o que é difícil de conseguir das empresas. O importante na academia é repassar conhecimento de negócios aos alunos, depois publicar, na minha opinião. No meu caso prefiro fazer relações de negócios e também ter um laço na academia. É importante considerar diferentes competências como ser professor e consultor (P3). Sobre o ensino e a investigação, precisamos de mais verba financeira para adquirir materiais de pesquisa e pagar bolsas aos alunos de mestrado e doutorado. Em um país como o Brasil, a bolsa de estudos é a que viabiliza a pesquisa para muitos alunos. Tem também a questão da pressão sobre publicação, que muitas vezes é elevada nos programas, principalmente os que tem mestrado e doutorado. O professor muitas vezes faz atividades administrativas e dá muitas aulas, o que torna o trabalho estressante (P9).

Em termos de dia a dia é um desafio o ensino superior. Temos os cargos de gestão e trabalho além das aulas e pesquisa. São muitos alunos, contatos com empresas, um trabalho invisível. Trabalho que absorve. Tenho muitas aulas e ainda investigação. E temos critérios de avaliação, somos avaliados. Temos que ter tempo para investigar e essa bolha pode arrebentar de um lado. Não temos tempo para ir a congressos para atualização, e que teríamos que ter. Existem também as limitações do orçamento. Fica na posição do favor. Os professores tem um papel importante em ligar o mercado e as universidades. Vejo também outro caso, que os professores de 40 ou mais anos estão entrando na carreira acadêmica, e de outro lado, professores novos de 30 ou menos anos. Acho que tem que ter um equilíbrio (P6).

Foi verificado nas falas dos professores relatos sobre a pressão enfrentada em desenvolver pesquisas que tenham resultados de publicações em journals de alto impacto. A percepção foi de que ocorre um excesso de trabalho, tanto do número de horas de aula 
que os professores necessariamente tem de ministrar, bem como dos trabalhos administrativos, e ainda, das pesquisas necessárias para desenvolvimento da carreira.

Tendo em vista a categoria 6 (envolvimento empresa $\mathrm{X}$ universidade $\mathrm{X}$ marketing) ocorreu unanimidade nas falas ao apontar que a importância de aproximar a universidade e os alunos para com as empresas é satisfatótio para o ensino e pesquisa de marketing.

As empresas precisam de fazer pesquisas de marketing. Vejo que as empresas podem auxiliar e fomentar a investigação, aliando o que precisam com o apoio às universidades e alunos (P8).

As empresas são os casos reais do marketing, portanto, muito importante a aproximação da universidade com as empresas. Incentivo muito os alunos a pesquisarem as empresas, produtos e serviços, e a trazerem os resultados para a sala de aula (P10).

Eu procuro envolver com notícias dos principais jornais e de artigos sobre o que ocorre nas empresas na área de marketing. Eu mesmo trabalhei por muito anos em empresas e procuro mostrar esta relação forte entre o marketing e as empresas na formação do aluno. Para que se tenha sucesso na carreira e para trazer resultados financeiros para as empresas os alunos devem entender o que o marketing pode fazer para melhorar os resultados das empresas (P1).

Todo trabalho de pesquisa tem de ser feito prioritariamente no local onde o aluno atua ou tem acesso à informação. Acho muito importante aproximar a pesquisa às empresas, para justamente relacionar a teoria à prática. Incentivo relatório de consultoria, plano de negócios e publicação de artigos (P7).

Para os professores, esta aproximação ajuda tanto as empresas que conseguem ter um pensamento mais crítico em relação aos problemas enfrentados, como auxilia os alunos na relação dos conhecimentos apreendidos com a prática dos negócios. Alguns professores relatam que convidam empresários e ex-alunos para realizarem participações em aulas e palestras, para estreitar esta relação universidade X empresa. Os professores de marketing sentem-se como incentivadores de contato entre universidade e empresa, pois o apoio das empresas pode resultar em mais publicações e pesquisas, e para a universidade, recursos financeiros e materiais sempre são bem vindos. Já para as empresas, conhecer os alunos acelera a possibilidade de futuras contratações de estagiários e funcionários.

\section{CONTRIBUIÇÕES DE PESQUISA E DISCUSSÕES}

Este tipo de pesquisa em que se estuda o trabalho do professor, costuma causar curiosidade e ao mesmo tempo reflexões em torno dos resultados. Afinal, parar um 
momento para ter uma visão do cotidiano da vida profissional do professor não ocorre a todo o momento. É muito importante para o professor observar e sentir como está sendo a realização de suas tarefas de trabalho, a que ponto anda as suas relações com os alunos e a instituição a qual é empregado, e como tem sido o desenvolvimento da sua carreira.

Observando o professor de marketing em específico, pela importância dos estudos de mercado, concorrência e principalmente de compreensão do consumidor, as empresas vem mostrando demanda por profissionais desta área, com destaque a partir da década de 1960. Efeitos da globalização econômica e internacionalização dos mercados, fez surgir também um professor capaz de ensinar e pesquisar este campo de conhecimento ao qual o marketing está presente. Estes fatos contribuíram até mesmo para um certo "glamour" que envolve a carreira do profissional de marketing, seja pela sua importância na tomada de decisões das empresas, seja pela necessidade de se ter uma visão mais crítica e de pesquisa nas instituições de ensino.

A contribuição em estudar e verificar como o professor de marketing trabalha no ensino e pesquisa tem relação direta com a formação do profissional que sai das universidades e iniciam suas carreiras nas mais diversas empresas. $\mathrm{O}$ papel de educação do professor de marketing vai além das salas de aula e laboratórios de pesquisa, pois está presente nas estratégias que ex-alunos executam na formulação de novos produtos e serviços para o mercado global. Os ensinamentos fornecidos aos alunos de marketing, conforme visto em parte neste artigo, mostra um conteúdo de interação necessário entre teoria e prática, passando necessariamente pelo contato universidade $\mathrm{X}$ empresa. Os professores de marketing entrevistados nos diferentes países, apontam para um conteúdo que envolvam disciplinas que sejam usuárias de tecnologia de informação e de ferramentas interativas, com aplicações que permitam o ensino tanto presencial quanto a distância eficientes e eficazes.

Em termos acadêmicos, o professor de marketing enquanto principal fornecedor de conhecimento em sala de aula, de acordo do que foi identificado nesta pesquisa, deve priorizar o conhecimento teórico com exemplos de casos reais de empresas na área de marketing, bem como convidar ou atrais gestores de marketing para relatar suas atividades de trabalho. A oportunidade de debate na academia sobre temas de marketing e a participação de profissionais convidados, enrique a experiência do conhecimento e dinamiza a relação professor-aluno. Ao desenvolver pesquisas aprofundadas sobre o professor de marketing e suas atividades de ensino e pesquisa, possibilitar ampliar a visão 
do que tem sido fornecido de conhecimento da área nas universidades e consequentemente aplicado pelas empresas. Portanto, acompanhar o trabalho do professor de marketing contribui para sugerir novas formas e estratégias de ensinoaprendizagem de marketing nos cursos de graduação, mestrado e doutorado na área.

\section{CONSIDERÇÕES FINAIS}

Diante de tentar entender o cotidiano do professor de marketing em universidades, chegou-se a questão-problema: De que forma é visto o ensino e a pesquisa de marketing na visão dos professores deste campo de conhecimento? Para tanto foi desenvolvida uma pesquisa exploratória, de natureza qualitativa, tendo como objetivo verificar, por meio da visão do professor de marketing universitário, como é considerado o seu trabalho no ensino e na pesquisa. Foram realizadas entrevistas pessoais no formato presencial e virtual, com 14 professores de marketing de 10 países de diferentes continentes.

Para responder ao objetivo de pesquisa foi necessário rever a teoria a respeito de estudos que tiveram como propósito o trabalho de ensino e pesquisa do professor de marketing. Com a base das pesquisas já realizadas sobre o tema, foi então elaborado um roteiro semiestruturado, o qual pudesse abranger o cotidiano do professor, tanto no ensino quanto na pesquisa de marketing. Foram criadas 6 categorias por meio da técnica de análise de conteúdo, obtendo assim dados como a frequência de palavras mais utilizadas pelos professores bem como percepções sobre as falas dos entrevistados.

Ao considerar o ensino, os professores de marketing consideram que os alunos possuem demandas semelhantes, tanto da graduação como dos mestrados e doutorados, como incentivar ligação entre teoria de marketing e casos de empresas, e também ter por parte dos professores técnicas de ensino-aprendizagem diversificadas e criativas, com uso de tecnologia. Aliás a tecnologia mostrou-se um dos principais pontos em que os alunos percebem as aulas e ensinamentos de forma mais atraente e motivante, cabendo ao professor saber trabalhar com sinergia o conteúdo de marketing com o apoio e uso de diferentes plataformas digitais. Além destes aspectos, boa parte dos professores disseram ter ou pretendem ter mais tempo para ligar o desenvolvimento sustentável ao marketing no ensino, bem como na pesquisa.

Os professores foram enfáticos ao citar a necessidade de uma atenção especial em atualizar conhecimentos e investir em leituras e estudos sobre o marketing. Leitura de 
artigos científicos, casos de ensino e necessidade de publicação em journals de impacto são percepções que se fazem fundamentais para construir uma boa carreira na área de pesquisa e ensino de marketing. Este fato que é considerado relevante ao mesmo tempo é preocupante, pois os professores citaram a pressão das faculdades e até mesmo pessoais em pesquisar e publicar em alto nível, o que traz em muitos casos estresse na carreira. Os entrevistados também relatam o acúmulo de funções como um dos possíveis casos de cansaço no trabalho, visto que além das aulas de graduação, especialização, mestrado e doutorado, os professores tem de criar e participar de grupos de pesquisa e extensão, além de publicar artigos e acumular cargos administrativos como coordenações e direções nas faculdades.

Em relação a pesquisa, os professores de marketing destacam a necessidade de apoio nas instituições de ensino, maior incentivo, e equipamentos e bolsas aos professores e alunos pesquisadores. Voltam a destacar a tecnologia como uma ferramenta indispensável, e para tal, precisam ter das faculdades infraestrutura material e humana, hardwares, softwares e equipe de pesquisadores motivados para os trabalhos. Os entrevistados citam a importância da ligação das universidades com as empresas, para que o investimento fosse distribuído entre estes dois agentes, visto que as empresas serão as maiores beneficiadas em ter recursos humanos de marketing preparados adequadamente pelos professores.

Outro aspecto relevante foi verificar as diferenças culturais que envolvem os professores de marketing de diferentes países. Os professores latino-americanos dizem como importante uma estrutura de apoio da faculdade, tanto em relação a ter mais bolsas de pesquisa e ensino como ter melhores condições de trabalho. Já os professores europeus se dizem mais preparados quanto estrutura de apoio da mesma forma que norteamericanos e asiáticos, mas por outro ponto, mostram-se preocupados com a necessidade de atrair mais os alunos para a sala de aula. Entretanto, para todos os professores entrevistados, independente do país e cultura, aspectos como pressão por resultados de publicação em journals de impacto, necessidade de maior contato entre faculdades e empresas, e maior investimento no professor, são pontos em comum.

Enquanto limitação de estudo, por ser esta uma pesquisa exploratória e qualitativa, foram coletadas percepções e falas de 14 professores de marketing, sendo desta forma, uma investigação não-conclusiva, sem caráter quantitativo e descritivo, mas que possui suas contribuições. Entretanto, como forma de apoio, decidiu-se também por realizar uma 
pesquisa quantitativa, a qual está em fase final. Espera-se com que ambas pesquisas, quali e quanti, mais ganhos sejam identificados sobre o professor de marketing.

Esta pesquisa mostrou-se gratificante não apenas pelos achados relativos às falas dos entrevistados, mas por apontar um perfil e características sobre o professor de marketing, quais sejam: uma construção de carreira na área significa ter um conjunto de diferentes esforços pessoais, como estudos constantes para manter atualizado o conhecimento, ter capacidade de ajustar e aglutinar a questão do ensino-aprendizagem com as ferramentas tecnológicas e, principalmente, destacar o prazer pela docência e pesquisa de marketing, no sentido de vocação.

Espera-se que esta pesquisa sobre o professor de marketing desperte outros grupos de pesquisa em diferentes países na continuação de compreender melhor o cotidiano do professor de Marketing. Estudar o professor e suas perspectivas e angústias, pode ser útil na formação de currículos de Marketing, auxiliando a formação de futuros gestores e pesquisadores da área.

\section{REFERÊNCIAS}

ALMEIDA, M. E. B.; ALONSO, M. (Orgs). Tecnologias na formação e na gestão escolar. São Paulo: Avercamp, 2007.

BACELLAR, C., IKEDA, A. Marketing professors: paths and perspectives. European Business Review, v. 18, n. 3, p. 231-242, 2006.

BACELLAR, F. C. T., IKEDA, A. A. Ensinar Marketing na visão de seus professores. Organizações \& Sociedade, 14(42), 151-165, 2007.

BARDIN, L. Análise de conteúdo. São Paulo: Edições 70, 2011.

BUCH, K., HUET, Y., RORRER, A., \& ROBERSON, L. Removing the Barriers to Full Professor: A Mentoring Program for Associate Professors. Change: The Magazine of Higher Learning, 43(6), 38-45, 2011.

COSTA, F. J., FILHO, J. M. S., LÔBO, R. J. S. Aluno como cliente e como produto: percepções e preferências dos alunos de ensino superior da área de negócios. Revista de Negócios, v. 16, n. 4, p. 91-106, out./dez, 2011.

CRESWELL, J. W. Projeto de Pesquisa: Métodos Qualitativo, Quantitativo e Misto, ed. 3. Porto Alegre: Artmed, 2010.

DE LA TORRE, S. Criatividade aplicada: recursos para uma formação criativa. São Paulo: Madras, 2008. 
DENZIN, N. K., \& LINCOLN, Y. S. Handbook of qualitative research. Thousand Oaks, CA: SAGE, 1994.

FREIRE, P. Pedagogia do oprimido, 17. ed. Rio de Janeiro: Paz e Terra, 1987.

GASKELL, G. Entrevistas individuais e grupais. In: M. W. Bauer, \& G. Gaskell (Orgs.), Pesquisa qualitativa com texto, imagem e som: um manual prático. Petrópolis: Vozes, 2002.

GRUBER, T., LOWRIE, A., BRODOWSKY, G. H., REPPEL, A. E., VOSS, R., \& CHOWDHURY, I. N. Investigating the Influence of Professor Characteristics on Student Satisfaction and Dissatisfaction. Journal of Marketing Education, 34(2), 165-178, 2012.

IKEDA, A. A.; BACELLAR, F. C. T. Revelando e Compreendendo o Relacionamento Professor-Aluno em Marketing. Revista de Administração Mackenzie, v. 9, n. 5, art. 204, p. 137-154, 2008.

JEPSON, E., \& FORREST, S. Individual contributory factors in teacher stress: The role of achievement striving and occupational commitment. British Journal of Educational Psychology, 76(1), 183-197, 2006.

KNOWLES, M. S.; HOLTON III, E. F.; SWANSON, R. A. Aprendizagem de resultados: uma abordagem prática para aumentar a efetividade da educação corporativa. Rio de Janeiro: Elsevier, 2009.

MALHOTRA, N. Pesquisa de marketing. 3.ed. Porto Alegre: Bookman, 2001.

MANZINI, E. J. A entrevista na pesquisa social. Didática, São Paulo, v. 26/27, pp. 149$158,1990$.

Peters, W. H. The Marketing Professor-Practitioner Gap: a possible solution. Journal of Marketing Education, 2(2), p. 4-11, 1980.

SOUZA, F. N., COSTA, A. P., MOREIRA, A. (2011). Análise de Dados Qualitativos Suportada pelo Software webQDA. Atas da VII Conferência Internacional de TIC na Educação: Perspectivas de Inovação (CHALLANGES 2011), pp. 49-56, Braga, 12 e 13 de maio.

VERGARA S. C. A formação em Administração como requisito para o exercício da função gerencial no Brasil. In: XXXI Enanpad, Rio de Janeiro. Anais... Rio de Janeiro: ANPAD, pp. 1-15, 2007.

Recebido em: 03/01/2022

Aprovado em: 30/01/2022

Publicado em: 01/02/2022 